\title{
Development of key performance indicators to evaluate centralized intake for patients with osteoarthritis and rheumatoid arthritis
}

Claire E. Barber ${ }^{*}$, Jatin N. Patel ${ }^{2}$, Linda Woodhouse ${ }^{3}$, Christopher Smith², Stephen Weiss ${ }^{2}$, Joanne Homik ${ }^{4,5}$, Sharon LeClercq ${ }^{1}$, Dianne Mosher ${ }^{1,4}$, Tanya Christiansen ${ }^{6}$, Jane Squire Howden ${ }^{7,8}$, Tracy Wasylak', James Greenwood-Lee ${ }^{10}$, Andrea Emrick ${ }^{2}$, Esther Suter ${ }^{11}$, Barb Kathol ${ }^{12}$, Dmitry Khodyakov ${ }^{13}$, Sean Grant ${ }^{13}$, Denise Campbell-Scherer ${ }^{14}$, Leah Phillips ${ }^{3}$, Jennifer Hendricks ${ }^{6}$ and Deborah A. Marshall ${ }^{10}$

\begin{abstract}
Introduction: Centralized intake is integral to healthcare systems to support timely access to appropriate health services. The aim of this study was to develop key performance indicators (KPIs) to evaluate centralized intake systems for patients with osteoarthritis (OA) and rheumatoid arthritis (RA).

Methods: Phase 1 involved stakeholder meetings including healthcare providers, managers, researchers and patients to obtain input on candidate KPIs, aligned along six quality dimensions: appropriateness, accessibility, acceptability, efficiency, effectiveness, and safety. Phase 2 involved literature reviews to ensure KPIs were based on best practices and harmonized with existing measures. Phase 3 involved a three-round, online modified Delphi panel to finalize the KPIs. The panel consisted of two rounds of rating and a round of online and in-person discussions. KPIs rated as valid and important ( $\geq 7$ on a 9-point Likert scale) were included in the final set.

Results: Twenty-five KPIs identified and substantiated during Phases 1 and 2 were submitted to 27 panellists including healthcare providers, managers, researchers, and patients in Phase 3. After the in-person meeting, three KPIs were removed and six were suggested. The final set includes 9 OA KPIs, 10 RA KPIs and 9 relating to centralized intake processes for both conditions. All $28 \mathrm{KPIs}$ were rated as valid and important.

Conclusions: Arthritis stakeholders have proposed $28 \mathrm{KPIs}$ that should be used in quality improvement efforts when evaluating centralized intake for OA and RA. The KPIs measure five of the six dimensions of quality and are relevant to patients, practitioners and health systems.
\end{abstract}

Keywords: Osteoarthritis, Rheumatoid arthritis, Health services research

\section{Introduction}

Arthritis is the leading cause of physical disability in Canada and the burden of arthritis, including osteoarthritis (OA) and rheumatoid arthritis (RA), is expected to increase over the next 30 years [1]. Timely diagnosis and appropriate treatment are associated with better outcomes for patients with arthritis. Patients with OA

\footnotetext{
* Correspondence: cehbarbe@ucalgary.ca

'Division of Rheumatology, Department of Medicine, University of Calgary, HRIC Room 3AA20, 3280 Hospital Drive NW, Calgary AB T2N 4Z6, Canada
} Full list of author information is available at the end of the article report less pain and improved quality of life and function following timely joint arthroplasties [2-4]. In RA, it is well established that early, targeted treatment with disease-modifying antirheumatic drugs (DMARDs) is associated with improved outcomes [5-7], which is a central component in evidence-based RA guidelines [8-11].

Unfortunately, many patients with $\mathrm{OA}$ and RA in Canada experience delays in access to care and treatment. The Canadian Institute for Health Information reports that the proportion of patients meeting wait time benchmarks for elective procedures (including hip and 
knee replacement) have remained largely unchanged over the last 3 years, and that many patients are not receiving care within recommended benchmarks [12]. In RA, national wait time data are lacking [13]; however, provincial studies suggest that access to rheumatologic care may be problematic because of workforce shortages [14-16].

The reasons for delays in care for appropriate treatment of patients with OA and RA are complex and include a mismatch between supply and demand for specialist care in many regions [14-17]. Furthermore, inefficiencies at the level of referral and triage can lead to delays in care [18]. Effective referral and intake management of this patient population is needed to ensure that the needs of patients are addressed in a timely, organized, transparent and consistent manner.

Centralized intake is a system that facilitates getting the right patients to the right providers at the right time by pooling patients into a single queue, assessing the nature and the urgency of referral, and prioritizing access to care based on the assessment of the referral $[19,20]$. Centralized intake systems that incorporate these elements of single-entry models and wait list management are key components to wait time reduction strategies [12]. These strategies have been shown to reduce wait times for specialty care and to improve the effective use of healthcare services [20-22].

The objective of the present work was to develop key performance indicators (KPIs) for use in evaluating centralized intake systems for arthritis care, starting with
$\mathrm{OA}$ and RA. For the purposes of this work, OA KPIs were focused on those patients with moderate to severe OA who required either surgical (total hip or knee arthroplasty) or nonsurgical management (requiring specialist consultation). The KPIs will be used to measure system improvements in the following dimensions of quality taken from the provincial quality framework [23]:

- Appropriateness: whether services are delivered according to best practices and relevant to user needs

- Accessibility: whether services are delivered in a timely manner

- Acceptability: whether services are responsive to user expectations and preferences

- Effectiveness: whether services are based on knowledge to achieve the best outcomes

- Efficiency: whether services are optimally used

\section{Methods}

The present work is part of a study to improve access to appropriate and effective arthritis care through collaboration with arthritis stakeholders. The KPIs for centralized intake of arthritis care were developed over three phases, as shown in Fig. 1 and described below.

\section{Phase 1: Establishing measurement priorities}

A series of arthritis stakeholder meetings were convened to define measurement priorities. Throughout

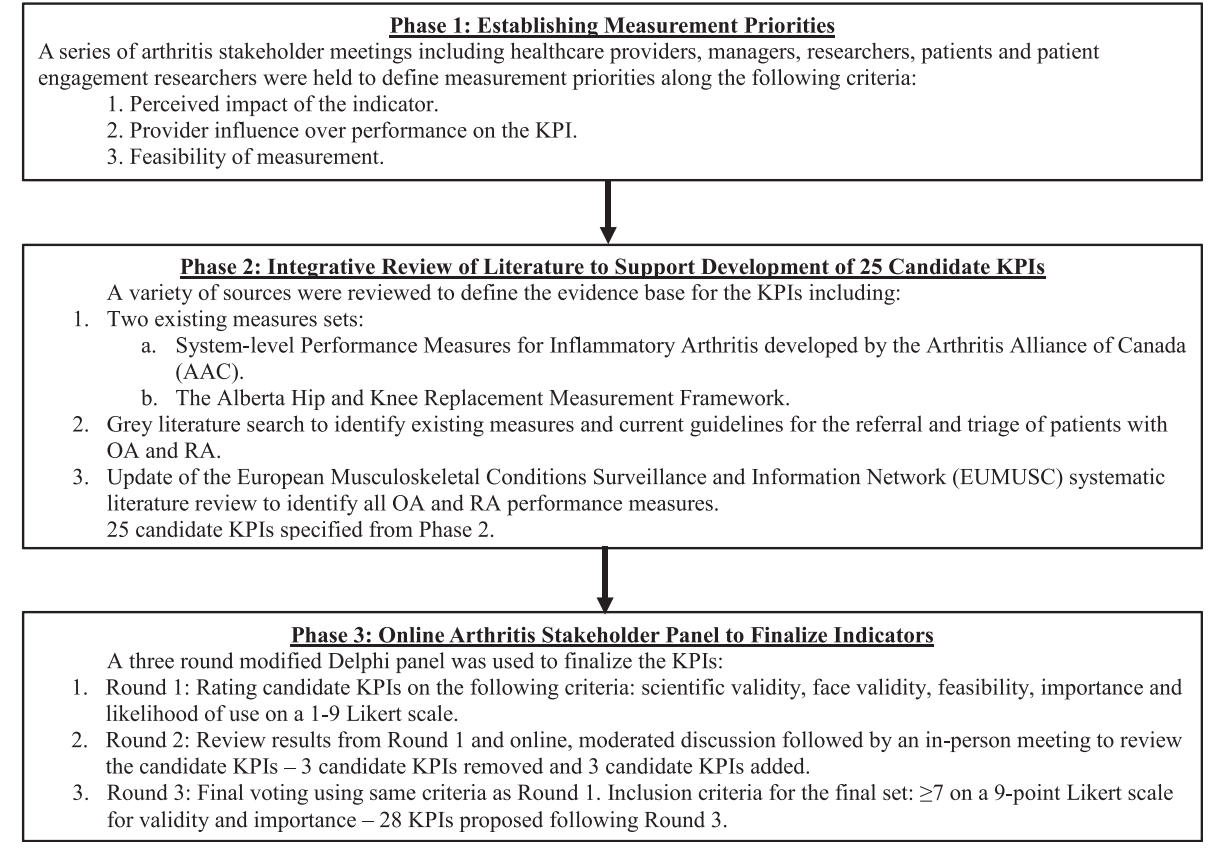

Fig. 1 Key performance indicator (KPI) development process. OA osteoarthritis, RA rheumatoid arthritis 
this process, the following stakeholder groups were represented: healthcare providers, managers, researchers, patients and patient engagement researchers. The following criteria were used to prioritize KPI development:

1. Perceived impact: Are there identifiable health benefits to patients who receive care, to care providers, and to the health system?

2. Provider influence over performance on the KPI: Is this factor under the control of a care provider, or can it lead to changes in the healthcare system?

3. Feasibility of measurement: Is the required information to measure performance available from data sources (e.g., electronic medical records or administrative data sets)?

\section{Phase 2: Integrative review of the literature to support candidate key performance indicators}

An integrative review of the literature $[24,25]$ was conducted to ensure that the 25 candidate KPIs were based on evidence and/or best practices and that they were harmonized with any existing published performance measures. The search strategy is shown in Additional file 1.

Briefly, the following sources were used to inform and support KPI development:

1. KPIs pertaining to RA were harmonized with the Arthritis Alliance of Canada (AAC) system-level performance measures for inflammatory arthritis (IA) [26].

2. Existing measures from the Alberta Hip and Knee Replacement Measurement Framework for measuring quality of care for hip and knee arthroplasty [27-29] were considered for inclusion in the harmonized set.

3. A grey literature search was conducted to identify existing measures and current guidelines for the referral and triage of patients with OA and RA by searching the websites of 33 arthritis organizations in North America, Europe, the United Kingdom and Australia.

4. We updated a recent systematic review of the literature conducted by the European Musculoskeletal Conditions Surveillance and Information Network [30] in two literature databases (MEDLINE and Embase) to identify all existing performance measures for OA and RA.

\section{Phase 3: Online arthritis stakeholder panel to finalize indicators}

To finalize the KPIs, a modification of the RAND-UCLA Appropriateness Method [31] was used during a three- round, online, modified Delphi procedure using an online platform called ExpertLens [32, 33].

\section{Panel composition and recruitment}

Twenty-eight panellists were invited to take part in Phase 3 of KPI development. All members of the panel were from Alberta, and they included healthcare providers (including rheumatologists, orthopaedic surgeons, primary care physicians and triage personnel), managers (including clinic managers and health administrators), and researchers and patients, including some who are trained in patient and community engagement research. Panellists were recruited to ensure representation from the major arthritis care centres as well as from large primary care networks and patient groups from across Alberta. No honoraria or incentives were offered for participation. The University of Calgary Conjoint Health Research Ethics Board approved this study (REB130822_MOD5), and the RAND Corporation's Human Subjects Protection Committee exempted the study from review (study identifier 2015-0005). The participants in this study provided consent to participate and for us to publish the study findings.

\section{Panel protocol}

In round 1, panellists rated the candidate KPIs anonymously using the online ExpertLens platform. In round 2, panellists reviewed the results of the round 1 voting and were given the opportunity to participate anonymously in an asynchronous online discussion about the candidate KPIs. Following this, an in-person meeting was held to review votes and comments on each KPI from rounds 1 and 2. By consensus, some KPIs were removed and others were modified or added to better reflect the measurement priorities. Minor modifications to wording or specification of the remaining KPIs were made. In round 3, panellists voted again on the modified KPI set using the same questions asked in round 1 .

After reviewing a background document that described the KPI development process, rationale for measurement, and supporting information, the panellists rated each KPI based on the following criteria on a 9-point Likert-type rating scale:

1. Scientific validity: How strong is either the scientific evidence or professional consensus supporting this indicator?

2. Face validity: How likely is it that better performance on the proposed indicator reflects a higher-quality health system?

3. Feasibility: How likely is it that the information required to report on this indicator will be available in your health system? 
4. Importance: How important is it to measure and report on this indicator when evaluating centralized intake for arthritis care?

5. Likelihood of use: How likely is it that you would use, or encourage the use of, this indicator for quality improvement in your centre?

For the KPIs that were harmonized with the AAC performance measures, validity was already established using a similar process [26]; therefore, participants were asked to answer only questions 3,4 and 5 .

\section{Analysis of panellist responses}

To be included in the final set, the KPIs had to be rated as highly scientifically valid and of high importance (questions 1 and 4, median ratings $\geq 7$ on a 9-point scale with no disagreement). Disagreement was calculated according to the RAND/UCLA Appropriateness Method handbook [31]. Disagreement exists when the interpercentile range (IPR) (difference between the 30th and 70th percentiles) is larger than the Interpercentile Range Adjusted for Symmetry (IPRAS), which was calculated using the formulae: $\mathrm{IPRAS}=2.35+$ [asymmetry index $(\mathrm{AI}) \times 1.5$ ] [31], where the AI is the absolute difference between 5 and the central point of the IPR (IPRCP) [31, 34].

Similarly, to include the KPIs that were harmonized with the AAC measures in the final set, there had to be agreement on the importance and likelihood of use (median ratings $\geq 7$ on a 9-point scale).
The feasibility of measuring and reporting on all the identified KPIs will be tested in later studies and may vary for different centres within Alberta. Thus, high feasibility (median ratings $\geq 7$ without disagreement) was not a requirement for inclusion in the final set. However, where there was evidence of panellist uncertainty regarding the feasibility of KPI measurement (median ratings of 4-6 on question 3), KPIs have to be deemed important and highly likely to be used as indicators for quality improvement (median ratings $\geq 7$ on a 9-point scale with no disagreement) to be included in the final set.

\section{Results}

\section{Establishing measurement priorities (Phase 1)}

An overview of the process used to establish measurement priorities is shown in Fig. 1. In summary, the major strategic decisions made regarding the scope of the measures included the following:

1. The KPIs were selected to capture important steps along the continuum of care between referral submission to diagnosis and treatment (see Fig. 2). The stakeholders acknowledged that guidelines and high-quality evidence might be lacking for measurement of some of the candidate KPIs (e.g., measuring time from receipt of referral to completion, or measuring patient or provider experience with centralized intake). Therefore, professional consensus was deemed an acceptable

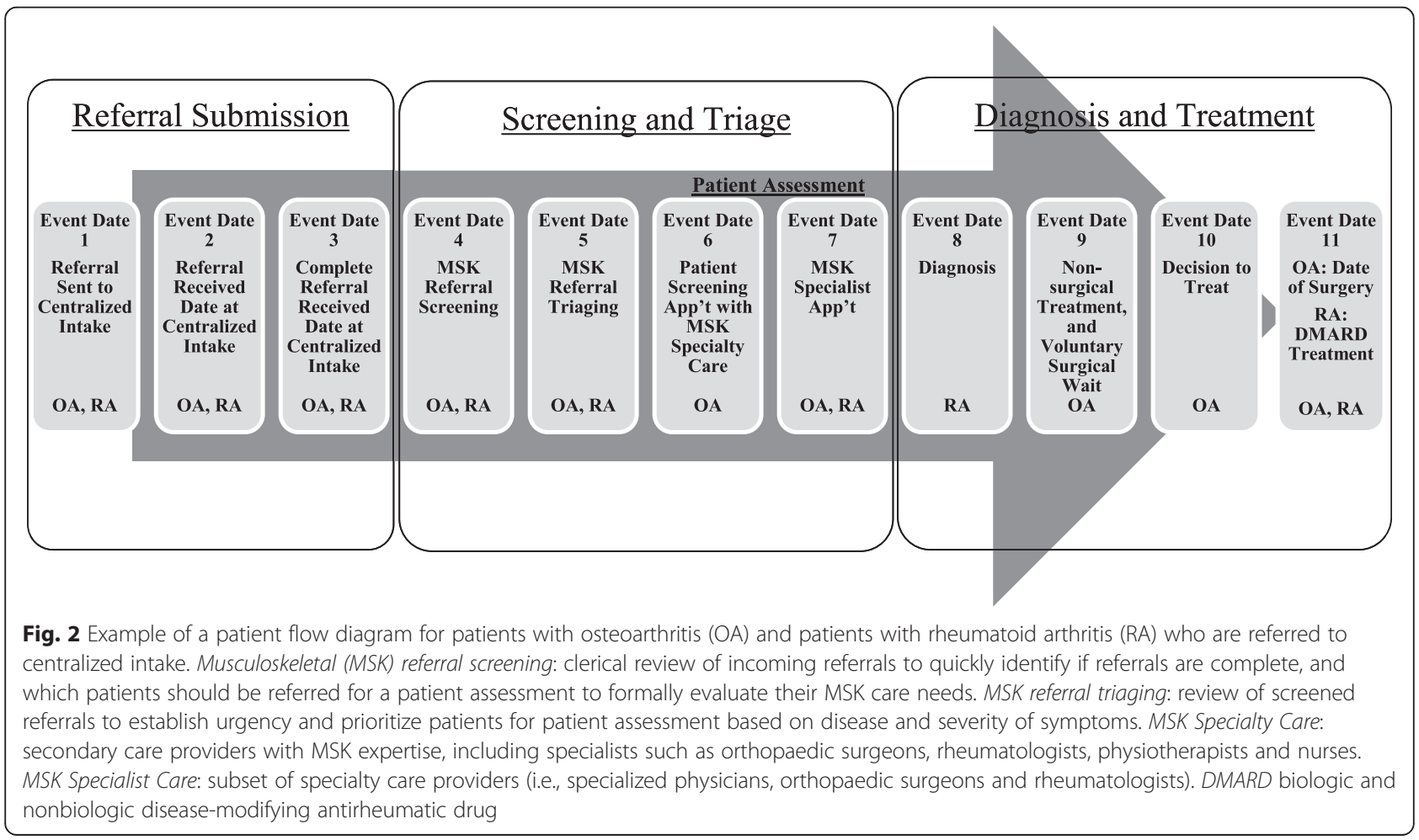


level of evidence for development and inclusion of such candidate KPIs.

2. Although the stakeholders anticipate that, by improving access to care and treatment, patient outcomes will improve, measurement of long-term patient outcomes was felt to be outside the scope of the present project.

3. Although all dimensions of quality of care were considered, safety indicators (such as drug monitoring) would not be part of the final KPI set. This decision was made because the role of centralized intake is to facilitate access to the most appropriate provider in a timely fashion, but it does not necessarily include treatment of patients and subsequent safety monitoring.

As a result of Phase 1, 25 KPIs were suggested for further development based on the criteria for prioritization and the strategic decisions listed above.

\section{Integrative literature review (Phase 2)}

Thirteen KPIs were harmonized with existing measures (see Table 1 for measure sources). The remainder of the KPIs were supported by guidelines or evidence supporting best practices for centralized intake found in our integrative review (full review results available upon request).

Online modified Delphi procedure to finalize KPIs (Phase 3) The candidate set submitted for panel evaluation is shown in Table 1. It included KPIs to address performance of centralized intake in the following categories: seven OA-specific KPIs, ten RA-specific KPIs and eight KPIs that apply to centralized intake systems for both conditions.

\section{Response rates and participant demographics}

Twenty-four (85.7 \%) of the twenty-eight invitees participated in round 1 of the modified Delphi process, and twenty-three $(82.1 \%)$ participated in round 3. Four participants participated in round 1 but not in round 3 , and three participants participated in round 3 but not in round 1. In total, 27 (96.4\%) of the 28 invitees participated in at least one round. During round 2, 12 participants $(42.9 \%)$ contributed to the online platform discussion and $19(67.9 \%)$ contributed during the inperson meeting. One of the participants who participated in the online discussion was not present at the meeting, so the total participation rate during round 2 was $20(71.4 \%)$.

Twenty-six participants $(93 \%)$ provided basic demographic information: ten (39\%) were physicians (four primary care physicians, four rheumatologists and two orthopaedic surgeons); three were patient representatives, including some patient engagement researchers (12\%); one was a triage nurse (4\%); four were researchers $(15 \%)$; four were healthcare managers $(15 \%)$; and four described themselves as 'other' (15\%). Twenty-five participants provided information about their geographic area. Eleven were from Calgary (44\%), nine were from Edmonton (36 \%) and five were from other regions in Alberta (20\%).

\section{Results from online provincial panel to finalize KPIs (Phase 3, round 2)}

During the round 2 in-person meeting, the results from round 1 and the online discussion part of round 2 were reviewed (data available upon request). Based on discussion of the results of these previous rounds, some modifications to the KPI set were made (Table 1). Three of the original KPIs were removed from the final round of voting by consensus. KPI 9 (orthopaedic surgeons per 100,000 population) was excluded because panellists felt there were better ways of capturing surgical capacity; they suggested alternate KPIs (see description below for KPIs 26 and 27). KPI 15 (percentage of RA referrals assessed using a priority tool) was excluded due to concerns of overly burdening the referring physicians. KPI 16 (percentage of RA referrals categorized as early RA) was excluded, as it was deemed not sufficiently important and was superseded by the other KPIs relating to wait times to receive care.

The panellists also recommended a number of new KPIs that more effectively captured the measurement priorities. KPI 26 (ratio of patient flow to estimated clinic capacity of OA teams participating in centralized intake) and KPI 27 (operating room time for arthroplasty surgeons in Alberta) were added to more adequately reflect the capacity for complex OA care. Together, they replaced the number of orthopaedic surgeons per 100,000 population (KPI 9). The analogous RA KPI-rheumatologists per 100,000 population (KPI 10) -was still included because of greater concern regarding rheumatologist capacity to provide high-quality RA care. An additional RA indicator, KPI 28 (ratio of patient flow to clinic capacity of RA teams participating in centralized intake) was added to capture clinic capacity.

To capture acceptability of centralized intake, the original set of KPIs included three indicators (KPIs 23-25) that measured the patient, referring clinician and arthritis specialty provider's experience with the centralized intake system. The panellists felt that the administrative staff and allied health professionals should also be included in a separate indicator and thus suggested KPI 29 (administrative staff and allied health professional experience with centralized intake).

The panellists related that an important function of centralized intake is ensuring that patients are appropriately triaged based on the suspected diagnosis and the 
Table 1 Key performance indicators for musculoskeletal centralized intake

\begin{tabular}{|c|c|c|c|}
\hline Key performance indicator & $\begin{array}{l}\text { Dimension of } \\
\text { quality of care }\end{array}$ & $\begin{array}{l}\text { Derived from existing } \\
\text { measure }\end{array}$ & $\begin{array}{l}\text { Included or removed } \\
\text { after round } 2\end{array}$ \\
\hline $\begin{array}{l}\text { 1. Time from osteoarthritis referral receipt to referral completion for } \\
\text { initially incomplete referrals }\end{array}$ & $\begin{array}{l}\text { Accessibility, } \\
\text { efficiency }\end{array}$ & New KPI & Included \\
\hline $\begin{array}{l}\text { 2. Time from rheumatoid arthritis referral receipt to referral completion for } \\
\text { initially incomplete referrals }\end{array}$ & $\begin{array}{l}\text { Accessibility, } \\
\text { efficiency }\end{array}$ & New KPI & Included \\
\hline $\begin{array}{l}\text { 3. Percentage of osteoarthritis referrals received with complete } \\
\text { information }\end{array}$ & Efficiency & $\begin{array}{l}\text { Hip and Knee Replacement } \\
\text { Measurement Framework }{ }^{\mathrm{a}, \mathrm{b}}\end{array}$ & Included \\
\hline $\begin{array}{l}\text { 4. Percentage of rheumatoid arthritis referrals received with complete } \\
\text { information }\end{array}$ & Efficiency & New KPI & Included \\
\hline $\begin{array}{l}\text { 5. Time from receipt of complete osteoarthritis referral to musculoskeletal } \\
\text { appointment }\end{array}$ & Accessibility & $\begin{array}{l}\text { Hip and Knee Replacement } \\
\text { Measurement Framework }{ }^{\mathrm{a}, \mathrm{b}}\end{array}$ & Included \\
\hline $\begin{array}{l}\text { 6. Waiting times for rheumatologist consultation for patients with new- } \\
\text { onset rheumatoid arthritis }\end{array}$ & Accessibility & $\begin{array}{l}\text { AAC Performance measures } \\
\text { for } I^{c}\end{array}$ & Included \\
\hline $\begin{array}{l}\text { 7. Time to disease-modifying antirheumatic drug therapy for patients with } \\
\text { new-onset rheumatoid arthritis }\end{array}$ & $\begin{array}{l}\text { Accessibility, } \\
\text { effectiveness }\end{array}$ & $\begin{array}{l}\text { AAC Performance measures } \\
\text { for } I A^{c}\end{array}$ & Included \\
\hline $\begin{array}{l}\text { 8. Percentage of patients with new-onset rheumatoid arthritis with at } \\
\text { least one visit to a rheumatologist in the first year of diagnosis }\end{array}$ & Accessibility & $\begin{array}{l}\text { AAC Performance measures } \\
\text { for } I A^{C}\end{array}$ & Included \\
\hline 9. Orthopaedic surgeons per 100,000 population & Accessibility & $C O A^{d, e}, A_{A O S}^{f}, A C R E U^{e, g}$ & Removed \\
\hline 10. Rheumatologists per 100,000 population & Accessibility & $\begin{array}{l}\text { AAC Performance measures } \\
\text { for } I A^{C}\end{array}$ & Included \\
\hline $\begin{array}{l}\text { 11. Percentage of patients that receive information regarding resources } \\
\text { and tools available for management while waiting for first } \\
\text { musculoskeletal specialty contact }\end{array}$ & Appropriateness & $\begin{array}{l}\text { Hip and Knee Replacement } \\
\text { Measurement Framework }{ }^{\mathrm{a}, \mathrm{b}}\end{array}$ & Included \\
\hline $\begin{array}{l}\text { 12. Percentage of osteoarthritis referrals scored using Western Canada } \\
\text { Waiting List priority referral criteriah }\end{array}$ & Appropriateness & New KPI & Included \\
\hline $\begin{array}{l}\text { 13. Distribution of osteoarthritis referrals in each urgency category (as } \\
\text { scored using the Western Canada Waiting List referral tool) }\end{array}$ & Appropriateness & New KPI & Included \\
\hline $\begin{array}{l}\text { 14. Percentage of osteoarthritis referrals triaged as highest urgency based } \\
\text { on high Western Canada Waiting List priority criteria scores seen within } \\
\text { Wait Time Alliance benchmarks }\end{array}$ & Appropriateness & New KPI & Included \\
\hline $\begin{array}{l}\text { 15. Percentage of rheumatoid arthritis referrals assessed using a priority } \\
\text { tool }\end{array}$ & Appropriateness & New KPI & Removed \\
\hline $\begin{array}{l}\text { 16. Percentage of rheumatoid arthritis referrals categorized as early } \\
\text { rheumatoid arthritis }\end{array}$ & Appropriateness & New KPI & Removed \\
\hline 17. Waiting times for patients with established rheumatoid arthritis & Accessibility & New KPI & Included \\
\hline $\begin{array}{l}\text { 18. Percentage of rheumatoid arthritis patients treated with a disease- } \\
\text { modifying antirheumatic drug during the measurement year }\end{array}$ & $\begin{array}{l}\text { Effectiveness, } \\
\text { accessibility }\end{array}$ & $\begin{array}{l}\text { AAC Performance measures } \\
\text { for } I A^{C}\end{array}$ & Included \\
\hline $\begin{array}{l}\text { 19. Percentage of referrals rejected or redirected when received at } \\
\text { centralized intake }\end{array}$ & Appropriateness & New KPI & Included \\
\hline 20. Percentage of musculoskeletal appointments completed as scheduled & Efficiency & $\begin{array}{l}\text { Hip and Knee Replacement } \\
\text { Measurement Framework }{ }^{\mathrm{a}, \mathrm{b}}\end{array}$ & Included \\
\hline 21. Percentage of specialist providers participating in centralized intake & Efficiency & New KPI & Included \\
\hline 22. Number of referrals received through centralized intake & Efficiency & New KPI & Included \\
\hline 23. Patient experience with centralized intake & Acceptability & $\begin{array}{l}\text { AHRQ', NHS, and Ministry of } \\
\text { Health and Long-Term Care } \\
\text { (Ontario) }^{k}\end{array}$ & Included \\
\hline 24. Referring clinician experience with centralized intake & Acceptability & $\begin{array}{l}\text { The Ministry of Health and } \\
\text { Long-Term Care (Ontario) }\end{array}$ & Included \\
\hline $\begin{array}{l}\text { 25. Musculoskeletal specialty care provider experience with centralized } \\
\text { intake }\end{array}$ & Acceptability & $\begin{array}{l}\text { The Ministry of Health and } \\
\text { Long-Term Care (Ontario) }\end{array}$ & Included \\
\hline $\begin{array}{l}\text { 26. Ratio of patient flow to estimated clinic capacity of osteoarthritis } \\
\text { teams participating in centralized intake }\end{array}$ & $\begin{array}{l}\text { Efficiency, } \\
\text { accessibility }\end{array}$ & Developed during round 2 & N/A \\
\hline 27. Operating room time for arthroplasty surgeons in Alberta & Accessibility & Developed during round 2 & N/A \\
\hline
\end{tabular}


Table 1 Key performance indicators for musculoskeletal centralized intake (Continued)

\begin{tabular}{llll}
\hline $\begin{array}{l}\text { 28. Ratio of patient flow to clinic capacity of rheumatoid arthritis teams } \\
\text { participating in centralized intake }\end{array}$ & $\begin{array}{l}\text { Efficiency, } \\
\text { accessibility }\end{array}$ & Developed during round 2 & N/A \\
29. Administrative staff and allied health professional experience with & Acceptability & Developed during round 2 & N/A
\end{tabular}
centralized intake

30. Agreement of centralized intake suspected diagnosis of severe osteoarthritis cases (e.g., patients who are candidates for hip or knee joint replacements) versus confirmed diagnosis of severe osteoarthritis

31. Agreement of centralized intake suspected diagnosis versus confirmed Appropriateness, Developed during round 2 N/A diagnosis for rheumatoid arthritis

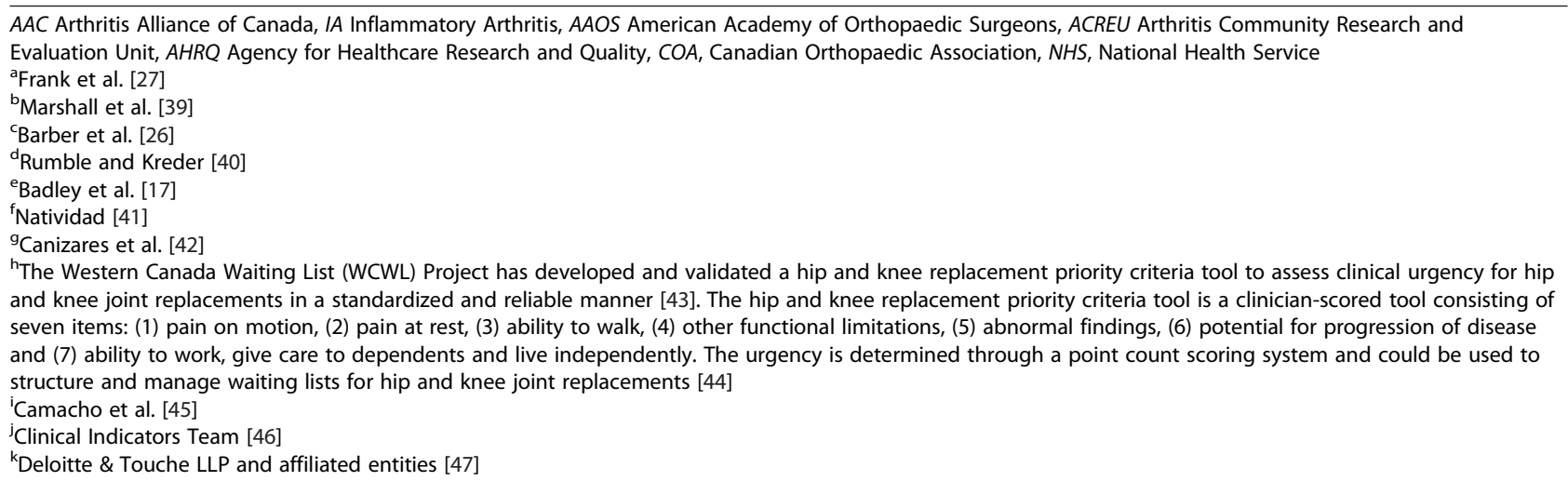

Table 2 Final round 3 voting on ten rheumatoid arthritis-specific key performance indicators for centralized intake

\begin{tabular}{|c|c|c|c|c|c|}
\hline & \multicolumn{5}{|c|}{$\begin{array}{l}\text { Median (range) and percentage of participants voting } \geq 7 \text { on } 1-9 \text { scale for each domain } \\
\text { ( } n=23 \text { unless otherwise specified) }\end{array}$} \\
\hline & $\begin{array}{l}\text { Scientific } \\
\text { validity }\end{array}$ & Face validity & $\begin{array}{l}\text { Feasibility: information } \\
\text { availability }\end{array}$ & Importance & $\begin{array}{l}\text { Likelihood of } \\
\text { use }\end{array}$ \\
\hline $\begin{array}{l}\text { KPI 2: Time from RA referral receipt to referral } \\
\text { completion for initially incomplete referrals }\end{array}$ & $7(5-8), 61 \%$ & $7(6-8), 74 \%$ & $8(6-8), n=22(64 \%)$ & $8(7-8), 78 \%$ & $7(6-8), 65 \%$ \\
\hline $\begin{array}{l}\text { KPI 4: Percentage of RA referrals received with } \\
\text { complete information }\end{array}$ & 7 (7-8), $78 \%$ & $8(7-8), 83 \%$ & $7(6-8), n=22(59 \%)$ & $\begin{array}{l}8(7-8), n=22 \\
(82 \%)\end{array}$ & $\begin{array}{l}7(6-8), n=22 \\
(68 \%)\end{array}$ \\
\hline $\begin{array}{l}\text { KPI 6: Waiting times for rheumatologist consultation } \\
\text { for patients with new-onset rheumatoid arthritis }\end{array}$ & $N / A^{a}$ & $N / A^{a}$ & $8(8-9), n=21(95 \%)$ & $\begin{array}{l}9(8-9), n=22 \\
(100 \%)\end{array}$ & $\begin{array}{l}9(9-9), n=22 \\
(100 \%)\end{array}$ \\
\hline $\begin{array}{l}\text { KPI 7: Time to disease-modifying antirheumatic } \\
\text { drug therapy for patients with new-onset RA }\end{array}$ & $N / A^{a}$ & $N / A^{a}$ & $7(6-8), n=22(68 \%)$ & $9(8-9), 91 \%$ & $\begin{array}{l}9(8-9), n=22 \\
(100 \%)\end{array}$ \\
\hline $\begin{array}{l}\text { KPI 8: Percentage of patients with new-onset RA } \\
\text { with at least one visit to a rheumatologist in the } \\
\text { first year of diagnosis }\end{array}$ & $N / A^{a}$ & $N / A^{a}$ & $7(6-8), n=21(57 \%)$ & $8(7-9), 78 \%$ & $8(7-8), 83 \%$ \\
\hline KPI 10: Rheumatologists per 100,000 population & $N / A^{a}$ & $N / A^{a}$ & $7(6-8), n=21(62 \%)$ & $\begin{array}{l}7(6-7), n=22 \\
(59 \%)\end{array}$ & $\begin{array}{l}7(5-7), n=21 \\
(52 \%)\end{array}$ \\
\hline $\begin{array}{l}\text { KPI 17: Waiting times for patients with } \\
\text { established RA }\end{array}$ & $8(8-9), 96 \%$ & 9 (8-9), $96 \%$ & $8(7-8), n=22(77 \%)$ & $8(8-9), 91 \%$ & $8(8-9), 96 \%$ \\
\hline $\begin{array}{l}\text { KPI 18: Percentage of rheumatoid arthritis patients } \\
\text { treated with a disease-modifying antirheumatic } \\
\text { drug during the measurement year }\end{array}$ & $N / A^{a}$ & $N / A^{a}$ & $8(6-9), 70 \%$ & $8(8-9), 83 \%$ & $9(8-9), 83 \%$ \\
\hline $\begin{array}{l}\text { KPI 28: Ratio of patient flow to clinic capacity of } \\
\text { RA teams participating in centralized intake }\end{array}$ & $\begin{array}{l}7(6-8), n=22 \\
(73 \%)\end{array}$ & $\begin{array}{l}8(7-8), n=22 \\
(82 \%)\end{array}$ & $7(5-8), n=22(55 \%)$ & $7(7-8), 83 \%$ & $\begin{array}{l}8(7-9), n=22 \\
(86 \%)\end{array}$ \\
\hline $\begin{array}{l}\text { KPI 31: Agreement of centralized intake suspected } \\
\text { diagnosis versus confirmed diagnosis of RA }\end{array}$ & $\begin{array}{l}8(6-8), n=21 \\
(71 \%)\end{array}$ & $8(6-8), 74 \%$ & $7(5-8), n=22(55 \%)$ & $\begin{array}{l}8(7-9), n=22 \\
(86 \%)\end{array}$ & $\begin{array}{l}8(7-9), n=21 \\
(76 \%)\end{array}$ \\
\hline
\end{tabular}

\section{$R A$ rheumatoid arthritis}

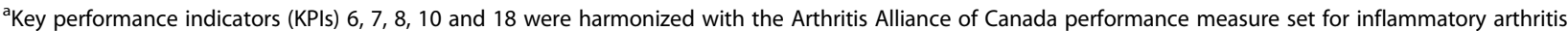
which used a similar process for development and scientific validity and face validity were not examined again in the present study 
information provided on the referral form. To assess this, KPIs related to the degree of agreement between the centralized intake suspected diagnosis and the specialist's final diagnosis were suggested by the panellists to be a critical component for evaluating the effectiveness of triage. Thus, two new indicators were added to evaluate the diagnostic agreement, one each for OA (KPI 30) and RA (KPI 31).

\section{Final round 3 voting}

A total of 28 KPIs were submitted for final voting in round 3. Ten RA-specific KPIs (Table 2), nine OAspecific KPIs (Table 3 ) and nine KPIs applied to centralized intake systems for both conditions (Table 4). All ten RA KPIs were rated as valid, feasible and important, with a high perceived likelihood of use (median ratings $\geq 7$ on a 9-point scale) and no disagreement according to the IPR > IPRAS rule. Similarly, seven of the nine KPIs for OA were rated highly in all domains, with two exceptions. KPI 12 (percentage of OA referrals scored using Western Canada Waiting List (WCWL) [35] priority referral criteria) had median scores of 6 for face validity and feasibility, and KPI 13 (distribution of OA referrals in each urgency category scored using the WCWL referral tool) had a median score of 6 in feasibility. Of the nine KPIs that applied to centralized intake systems in general, there was uncertainty regarding the feasibility of capturing three: KPI 11 (percentage of patients who receive information regarding resources and tools available for management while waiting for first musculoskeletal specialty contact), KPI 24 (referring clinician's experience with centralized intake) and KPI 25 (musculoskeletal specialty care provider experience with centralized intake). All other KPIs had median scores $\geq 7$ for validity, importance and likelihood of use, with no disagreement.

\section{Discussion}

Through a rigorous process involving arthritis stakeholders from across the Province of Alberta, we developed a set of 28 KPIs for evaluation of centralized intake methods for OA and RA care. The KPIs address five dimensions of the provincial quality framework [23], with the exception of safety, which was deemed outside the scope of this project. Our panellists rated the KPIs as highly valid and important. They also suggested that the indicators were highly likely to be used in the evaluation of centralized intake.

To our knowledge, this is the first set of KPIs specifically designed to assess centralized intake systems for arthritis care. Although developed within the context of Alberta, the KPIs are likely highly relevant to other

Table 3 Final round 3 voting on nine osteoarthritis-specific key performance indicators for centralized intake

\begin{tabular}{|c|c|c|c|c|c|}
\hline & \multicolumn{5}{|c|}{$\begin{array}{l}\text { Median (range) and percentage of participants voting } \geq 7 \text { on } 1-9 \text { scale for each } \\
\text { domain ( } n=23 \text { unless otherwise specified) }\end{array}$} \\
\hline & $\begin{array}{l}\text { Scientific } \\
\text { validity }\end{array}$ & Face validity & $\begin{array}{l}\text { Feasibility: information } \\
\text { availability }\end{array}$ & Importance & $\begin{array}{l}\text { Likelihood } \\
\text { of use }\end{array}$ \\
\hline $\begin{array}{l}\text { KPI 1: Time from OA referral receipt to referral } \\
\text { completion for initially incomplete referrals }\end{array}$ & $7(5-8), 65 \%$ & 7 (6-8), $74 \%$ & $8(6-8), n=22(68 \%)$ & 8 (7-8), $78 \%$ & 7 (6-8), $74 \%$ \\
\hline $\begin{array}{l}\text { KPI 3: Percentage of OA referrals received with } \\
\text { complete information }\end{array}$ & $7(6-8), 65 \%$ & $8(7-8), 83 \%$ & $7(6-8), n=22(73 \%)$ & 7 (7-8), $83 \%$ & $\begin{array}{l}7(6-8), n=22 \\
(64 \%)\end{array}$ \\
\hline $\begin{array}{l}\text { KPI 5: Time from receipt of complete OA referral } \\
\text { to musculoskeletal appointment }\end{array}$ & $8(8-9), 96 \%$ & $9(8-9), 100 \%$ & $8(7-9), n=22(86 \%)$ & $\begin{array}{l}9(8-9), n=22 \\
(100 \%)\end{array}$ & $\begin{array}{l}9(8-9), n=22 \\
(95 \%)\end{array}$ \\
\hline $\begin{array}{l}\text { KPI 12: Percentage of OA referrals scored using } \\
\text { Western Canada Waiting List priority referral criteria }\end{array}$ & $\begin{array}{l}7(6-7), n=22 \\
(73 \%)\end{array}$ & $\begin{array}{l}6(6-8), n=22 \\
(45 \%)\end{array}$ & $6(5-7), n=22(45 \%)$ & $\begin{array}{l}7(6-7), n=22 \\
(64 \%)\end{array}$ & $\begin{array}{l}7(6-7), n=22 \\
(59 \%)\end{array}$ \\
\hline $\begin{array}{l}\text { KPI 13: Distribution of OA referrals in each urgency } \\
\text { category (as scored using the Western Canada } \\
\text { Waiting List referral tool) }\end{array}$ & 7 (7-8), $83 \%$ & $7(6-8), 65 \%$ & $6(6-7), n=22(50 \%)$ & 7 (6-8), $74 \%$ & 7 (6-8), $61 \%$ \\
\hline $\begin{array}{l}\text { KPI 14: Percentage of OA referrals triaged as highest } \\
\text { urgency based on high Western Canada Waiting List } \\
\text { priority criteria scores seen within Wait Time Alliance } \\
\text { benchmarks }\end{array}$ & $8(7-8), 96 \%$ & $8(7-8), 91 \%$ & $7(6-7), n=22(59 \%)$ & $\begin{array}{l}7(7-8), n=21 \\
(95 \%)\end{array}$ & $8(7-8), 87 \%$ \\
\hline $\begin{array}{l}\text { KPI 26: Ratio of patient flow to estimated clinic capacity } \\
\text { of OA teams participating in centralized intake }\end{array}$ & $\begin{array}{l}7(6-7), n=22 \\
(64 \%)\end{array}$ & $8(7-8), 83 \%$ & $7(5-7), n=22(55 \%)$ & $\begin{array}{l}8(7-9), n=22 \\
(82 \%)\end{array}$ & $\begin{array}{l}8(7-9), n=22 \\
(82 \%)\end{array}$ \\
\hline $\begin{array}{l}\text { KPI 27: Operating room time for arthroplasty surgeons } \\
\text { in Alberta }\end{array}$ & $\begin{array}{l}7(6-8), n=20 \\
(55 \%)\end{array}$ & $\begin{array}{l}7(7-8), n=22 \\
(77 \%)\end{array}$ & $7(7-8), n=20(75 \%)$ & $\begin{array}{l}7(6-8), n=21 \\
(67 \%)\end{array}$ & $\begin{array}{l}7(5-8), n=21 \\
(67 \%)\end{array}$ \\
\hline $\begin{array}{l}\text { KPI 30: Agreement of centralized intake suspected } \\
\text { diagnosis of severe OA cases (e.g., patients who are } \\
\text { candidates for hip or knee joint replacements) versus } \\
\text { confirmed diagnosis of severe OA }\end{array}$ & $\begin{array}{l}8(7-8), n=21 \\
(81 \%)\end{array}$ & $\begin{array}{l}8(7-8), n=21 \\
(90 \%)\end{array}$ & $7(6-8), n=19(63 \%)$ & $\begin{array}{l}8(8-9), n=21 \\
(95 \%)\end{array}$ & $\begin{array}{l}8(8-9), n=19 \\
(89 \%)\end{array}$ \\
\hline
\end{tabular}


Table 4 Final round 3 voting on nine key performance indicators for centralized intake applicable to rheumatoid arthritis and osteoarthritis

\begin{tabular}{|c|c|c|c|c|c|}
\hline & \multicolumn{5}{|c|}{$\begin{array}{l}\text { Median (range) and \% of participants voting } \geq 7 \text { on a } 1-9 \text { scale for each domain ( } n=23 \\
\text { unless otherwise specified) }\end{array}$} \\
\hline & $\begin{array}{l}\text { Scientific } \\
\text { validity }\end{array}$ & $\begin{array}{l}\text { Face } \\
\text { validity }\end{array}$ & $\begin{array}{l}\text { Feasibility: information } \\
\text { availability }\end{array}$ & Importance & $\begin{array}{l}\text { Likelihood of } \\
\text { use }\end{array}$ \\
\hline $\begin{array}{l}\text { KPI 11: Percentage of patients who receive information } \\
\text { regarding resources and tools available for management } \\
\text { while waiting for first musculoskeletal specialty contact }\end{array}$ & $7(7-8), 78 \%$ & $\begin{array}{l}7(7-8) \\
91 \%\end{array}$ & $6(4-6), n=21(24 \%)$ & $\begin{array}{l}7(7-8), n=22 \\
(86 \%)\end{array}$ & $\begin{array}{l}8(7-8), n=22 \\
(77 \%)\end{array}$ \\
\hline $\begin{array}{l}\text { KPI 19: Percentage of referrals rejected or redirected } \\
\text { when received at centralized intake }\end{array}$ & $7(6-8), 74 \%$ & $\begin{array}{l}7(6-8), \\
70 \%\end{array}$ & $7(6-8), n=21(67 \%)$ & $7(7-8), 83 \%$ & $\begin{array}{l}7(7-8), n=22 \\
(77 \%)\end{array}$ \\
\hline $\begin{array}{l}\text { KPI 20: Percentage of musculoskeletal appointments } \\
\text { completed as scheduled }\end{array}$ & $7(6-8), 65 \%$ & $\begin{array}{l}8(7-8) \\
87 \%\end{array}$ & $7(6-8), n=22(64 \%)$ & $\begin{array}{l}9(8-9), n=21 \\
(81 \%)\end{array}$ & $\begin{array}{l}8(7-9), n=22 \\
(77 \%)\end{array}$ \\
\hline $\begin{array}{l}\text { KPI 21: Percentage of specialist providers participating } \\
\text { in centralized intake }\end{array}$ & $7(6-7), 70 \%$ & $\begin{array}{l}7(7-8), \\
78 \%\end{array}$ & $7(6-8), n=22(73 \%)$ & $8(7-8), 83 \%$ & $7(7-8), 83 \%$ \\
\hline $\begin{array}{l}\text { KPI 22: Number of referrals received through centralized } \\
\text { intake }\end{array}$ & 7 (7-8), $78 \%$ & $\begin{array}{l}8(7-8) \\
87 \%\end{array}$ & $9(7-9), n=21(81 \%)$ & $9(8-9), 100 \%$ & $\begin{array}{l}8(7-9), n=22 \\
(95 \%)\end{array}$ \\
\hline KPI 23: Patient experience with centralized intake & $7(7-8), 87 \%$ & $\begin{array}{l}8(8-9) \\
87 \%\end{array}$ & $7(5-8), 65 \%$ & $\begin{array}{l}9(8-9), n=22 \\
(95 \%)\end{array}$ & $9(8-9), 87 \%$ \\
\hline $\begin{array}{l}\text { KPI 24: Referring clinician's experience with centralized } \\
\text { intake }\end{array}$ & $7(7-8), 78 \%$ & $\begin{array}{l}8(7-8), \\
96 \%\end{array}$ & $5(5-7), 32 \%$ & $9(8-9), 96 \%$ & $9(7-9), 96 \%$ \\
\hline $\begin{array}{l}\text { KPI 25: Musculoskeletal specialty care provider experience } \\
\text { with centralized intake }\end{array}$ & $7(6-8), 70 \%$ & $\begin{array}{l}7(7-8), \\
91 \%\end{array}$ & $6(5-7), n=22(45 \%)$ & $8(7-9), 91 \%$ & $8(7-9), 96 \%$ \\
\hline $\begin{array}{l}\text { KPI 29: Administrative staff and allied health professional } \\
\text { experience with centralized intake }\end{array}$ & $\begin{array}{l}7(6-8), n=22 \\
(73 \%)\end{array}$ & $\begin{array}{l}8(7-8) \\
87 \%\end{array}$ & $7(5-7), n=22(59 \%)$ & $8(7-9), 83 \%$ & $\begin{array}{l}8(7-9), n=21 \\
(76 \%)\end{array}$ \\
\hline
\end{tabular}

KPI key performance indicator

arthritis and musculoskeletal care settings where centralized intake is feasible. The KPIs may also help to inform improvements in healthcare systems interested in developing centralized intake systems, although such systems may not be possible in all care settings (e.g., singlepractice settings). These KPIs may also be of interest to other specialty services.

The KPIs presented herein focus on OA and RA, although it was recognized that any centralized intake system for arthritis care is likely to receive referrals for other types of arthritis. OA and RA were chosen because these are the two most common arthritis conditions in the general population and represent prototypical inflammatory and non-inflammatory arthritis. There is also strong evidence that better access to care and treatment in these conditions leads to improved patient outcomes [2, 3, 5-7, 36, 37].

During the KPI development process, we decided a priori not to exclude KPIs with lower feasibility ratings (median scores of 4-6), reflecting the panellists' uncertainty about the availability of information. We did not want to exclude potentially important and relevant KPIs for which system changes could be implemented in the future to enable data capture. In total, two OA KPIs related to scoring the WCWL (KPIs 12 and 13), which is a prioritization tool for hip and knee OA surgical consultation [35], were rated as less feasible. During round 2 discussions, it became clear that although the WCWL is included on current triage forms for hip and knee surgical referrals in Alberta, the tool is not empirically scored. It was likely that panellists considered the feasibility of scoring the WCWL in this environment as uncertain because technology changes would be needed to implement scoring of the WCWL. For similar reasons, the face validity of KPI 12 was questioned (percentage of OA referrals scored using the WCWL priority referral criteria). That KPI was retained, however, because panellists indicated that it was sufficiently important and that they were highly likely to use it.

KPI 11 (percentage of patients who receive information regarding resources and tools available for management while waiting for first musculoskeletal specialty contact) also received lower feasibility scores. This is likely because there are few means of tracking which information patients receive while waiting for their appointment (beyond appointment scheduling information), and changes to existing clinical databases and triage processes would be needed to capture this KPI.

Similarly, the KPIs related to the referring clinician or specialty care provider (e.g., rheumatologist or orthopaedic surgeon) experience with centralized intake (KPIs 24 and 25) received lower feasibility ratings, as surveys capturing clinician experience are not routinely done in Alberta. Interestingly, there were higher ratings for KPIs capturing the experience of patients as well as administrative staff and allied health professionals. This may be 
because there are existing patient surveys already administered routinely in Alberta (especially for patients with OA). Furthermore, it was felt that administrative staff and allied health professionals were more easily surveyed than referring or specialty physicians.

\section{Conclusion}

We developed a set of 28 KPIs for evaluation of centralized intake for patients with OA and RA. The KPIs will be tested further for feasibility using existing data sources (e.g., administrative data and clinical databases) before widespread implementation. Once tested for feasibility, the KPIs will be used to develop and evaluate an optimal centralized intake system for arthritis care for OA and RA. Measuring the impact of changes to a centralized intake system using standardized metrics is critical for ongoing quality assurance and quality improvement in health systems [38], and this work represents a critical first step in optimizing access to healthcare delivery for patients with OA and RA.

\section{Additional file}

Additional file 1: Integrative literature review search strategy. The search strategy used for an integrative review of literature to ensure candidate key performance indicators were based on evidence and/or best practices, and that they were harmonized with any existing published performance measures. (DOCX 20 kb)

\begin{abstract}
Abbreviations
AAC: Arthritis Alliance of Canada; AAOS: American Academy of Orthopaedic Surgeons; ACREU: Arthritis Community Research and Evaluation Unit; AHRQ: Agency for Healthcare Research \& Quality; Al: asymmetry index; COA: Canadian Orthopaedic Association; DMARD: disease-modifying antirheumatic drug; IA: inflammatory arthritis; IPR: interpercentile range; IPRAS: Interpercentile Range Adjusted for Symmetry; KPI: key performance indicator; MSK: musculoskeletal; N/A: not applicable; NHS: National Health Service; OA: osteoarthritis; RA: rheumatoid arthritis; WCWL: Western Canada Waiting List.
\end{abstract}

\section{Competing interests}

CEB is a doctoral candidate and held a Vanier Canada Graduate Scholarship (2014-31 May 2015) as well as a Health Research Clinical Fellowship from Alberta Innovates Health Solutions (AlHS; 2011-31 May 2015). From 2011 to 2013, her doctoral work was also supported by a rheumatology postgraduate fellowship funded by UCB Canada, the Canadian Rheumatology (CRA) Association, and The Arthritis Society (TAS). LW is the President and a member of the Board of Directors of the Canadian Physiotherapy Association. DAM is supported through a Canadian Institutes for Health Research Canada Research Chair in Health Services and Systems Research and the Arthur J. E. Child Chair in Rheumatology Outcomes Research.

\section{Authors' contributions}

CEB designed the study methodology, coordinated the study, led data collection, performed statistical analysis, interpreted the results, inferenced conclusions from the results, and drafted the manuscript. JNP coordinated the study, contributed to data collection, and helped to draft the manuscript. LW conceived the study, contributed important intellectual content from a healthcare system perspective, and helped to draft the manuscript. CS conceived the study, participated in the design of the study methodology, contributed important intellectual content from a healthcare system perspective, and helped to draft the manuscript. SW participated in the design of the study methodology, contributed to data collection, contributed important intellectual content from a healthcare system perspective, and helped to draft the manuscript. JHo participated in the design of the study methodology, contributed important intellectual content from a care provider's perspective, and helped to draft the manuscript. SLC participated in the design of the study methodology, contributed important intellectual content from a care provider's perspective, and helped to draft the manuscript. DM participated in the design of the study methodology, contributed important intellectual content from a care provider's perspective, and helped to draft the manuscript. TC participated in the design of the study methodology, contributed important intellectual content from a healthcare system perspective, and helped to draft the manuscript. JSH participated in the design of the study methodology, contributed important intellectual content from a healthcare system perspective, and helped to draft the manuscript. TW conceived the study, participated in the design of the study methodology, contributed important intellectual content from a healthcare system perspective, and helped to draft the manuscript. JGL participated in the design of the study methodology, contributed important intellectual content from a researcher's perspective, and helped to draft the manuscript. AE participated in the design of the study methodology, contributed important intellectual content from a healthcare system perspective, and helped to draft the manuscript. ES participated in the design of the study methodology, contributed important intellectual content from a healthcare system perspective, and helped to draft the manuscript. BK participated in the design of the study methodology, contributed important intellectual content from a healthcare system perspective, and helped to draft the manuscript. DK participated in the design of the study methodology, contributed to data collection, performed statistical analysis, critically reviewed the manuscript, and helped to draft the manuscript. SG participated in the design of the study methodology, contributed to data collection, performed statistical analysis, critically reviewed the manuscript, and helped to draft the manuscript. DCS contributed important intellectual content from a care provider's perspective and helped to draft the manuscript. LP contributed important intellectual content from a healthcare system perspective and helped to draft the manuscript. JHe participated in the design of the study methodology, contributed important intellectual content from a healthcare system perspective, and helped to draft the manuscript. DAM conceived the study, designed the study methodology, coordinated the study, contributed to data collection, performed statistical analysis, and drafted the manuscript. All authors read and approved the final manuscript.

\section{Acknowledgements}

Gordon Arnett, MD, FRCS(C), Division of Orthopaedic Surgery, University of Alberta, Edmonton, AB, Canada

Theresa Lupton, RN, CCRP, Nurse Clinician Rheumatology, Central Triage, Richmond Road Diagnostic \& Treatment Centre, Alberta Health Services Calgary, AB, Canada

Jean Miller, PhD, patient and community engagement researcher, and osteoarthritis patient

Sylvia Teare, MEd, patient and community engagement researcher, and osteoarthritis patient

Mandy Atwood, rheumatoid arthritis patient

Yolanda Martens Van Hilst, RN, Program Manager, Service Delivery, Calgary Foothills Primary Care Network, Calgary, AB, Canada

Tobias Gelber, MD, CCFP, The Associate Clinic, Pincher Creek, AB, Canada Steve Chambers, MD, LMCC, The Allin Clinic, Edmonton, and Department of Family Medicine, University of Alberta, Edmonton, AB, Canada Lauren Jewett, Research Assistant, Department of Community Health Sciences, University of Calgary, Calgary, AB, Canada Colleen Enns, Executive Director, Edmonton Oliver Primary Care Network, Edmonton, AB, Canada

Christal Lacombe, Program Manager, Service Delivery, Calgary Foothills Primary Care Network, Calgary, AB, Canada

Mark Fernhout, MD, FRCS(C), Lethbridge Orthopaedics, Lethbridge, AB, Canada

Stephen Aaron, MD, FRCPC, Division of Rheumatology Chief, University of Alberta, Edmonton, AB, Canada

The late Pamela M. Barton, MD, FRCPC, Clinical Associate Professor, Division of Physical Medicine and Rehabilitation, University of Calgary, Calgary, AB, Canada 


\section{Author details}

'Division of Rheumatology, Department of Medicine, University of Calgary, HRIC Room 3AA20, 3280 Hospital Drive NW, Calgary AB T2N 4Z6, Canada. ${ }^{2}$ Alberta Bone and Joint Health Institute, Calgary, AB, Canada. ${ }^{3}$ Faculty of Rehabilitation Medicine, University of Alberta, Edmonton, AB, Canada. ${ }^{4}$ Arthritis Working Group, Bone and Joint Health Strategic Clinical Network, Calgary and Edmonton, $A B$, Canada. ${ }^{5}$ Division of Rheumatology, University of Alberta, Edmonton, AB, Canada. ${ }^{6}$ Alberta Hip and Knee Clinic, Calgary, AB, Canada. ${ }^{7}$ Edmonton Musculoskeletal Centre, Edmonton, AB, Canada. ${ }^{8} \mathrm{Hip}$ and Knee Working Group, Bone and Joint Health Strategic Clinical Network, Calgary and Edmonton, AB, Canada. ${ }^{9}$ Strategic Clinical Networks, Alberta Health Services, Calgary, AB, Canada. ${ }^{10}$ Department of Community Health Sciences, University of Calgary, Calgary, AB, Canada. ${ }^{11}$ Workforce Research and Evaluation, Alberta Health Services, Calgary, AB, Canada. ${ }^{12}$ Foothills Medical Centre, Alberta Health Services, Calgary, AB, Canada. ${ }^{13}$ The RAND Corporation, Santa Monica, CA, USA. ${ }^{14}$ Department of Family Medicine, University of Alberta, Edmonton, AB, Canada.

\section{Received: 16 September 2015 Accepted: 29 October 2015 Published online: 14 November 2015}

\section{References}

1. Bombardier C, Hawker G, Mosher D. The impact of arthritis in Canada: today and over the next 30 years. Toronto: Arthritis Alliance of Canada; 2011. http://www.arthritisalliance.ca/images/PDF/eng/Initiatives/20111022_ 2200 impact of arthritis.pdf. Accessed 5 Nov 2015.

2. Desmeules F, Dionne CE, Belzile ÉL, Bourbonnais R, Frémont P. The impacts of pre-surgery wait for total knee replacement on pain, function and healthrelated quality of life six months after surgery. J Eval Clin Pract. 2012;18:111-20.

3. Desmeules F, Dionne CE, Belzile É, Bourbonnais R, Frémont P. The burden of wait for knee replacement surgery: effects on pain, function and healthrelated quality of life at the time of surgery. Rheumatology (Oxford). 2010;49:945-54.

4. Ackerman $\mathrm{IN}$, Bennell $\mathrm{KL}$, Osborne RH. Decline in health-related quality of life reported by more than half of those waiting for joint replacement surgery: a prospective cohort study. BMC Musculoskelet Disord. 2011;12:108.

5. Lard LR, Visser $H$, Speyer I, Vander Horst-Bruinsma IE, Zwinderman AH, Breedveld FC, et al. Early versus delayed treatment in patients with recentonset rheumatoid arthritis: comparison of two cohorts who received different treatment strategies. Am J Med. 2001;111:446-51.

6. Nell VP, Machold KP, Eberl G, Stamm TA, Uffmann M, Smolen JS. Benefit of very early referral and very early therapy with disease-modifying antirheumatic drugs in patients with early rheumatoid arthritis. Rheumatology (Oxford). 2004:43:906-14.

7. van der Linden MP, le Cessie S, Raza K, van der Woude D, Knevel R, Huizinga TW, et al. Long-term impact of delay in assessment of patients with early arthritis. Arthritis Rheum. 2010;62:3537-46.

8. Bykerk VP, Akhavan P, Hazlewood GS, Schieir O, Dooley A, Haraoui B, et al. Canadian Rheumatology Association recommendations for pharmacological management of rheumatoid arthritis with traditional and biologic diseasemodifying antirheumatic drugs. J Rheumatol. 2012;39:1559-82.

9. Bykerk VP, Baron M, Boire G, Haraoui B, Khrashi M, LeClerca S, et al. Canadian Consensus Statement on Early Optimal Therapy in Early Rheumatoid Arthritis. CRAJ J Can Rheumatol Assoc. 2004;14 Autumn:11-3.

10. Smolen JS, Landewé R, Breedveld FC, Buch M, Burmester G, Dougados M, et al. EULAR recommendations for the management of rheumatoid arthritis with synthetic and biological disease-modifying antirheumatic drugs: 2013 update. Ann Rheum Dis. 2014;73:492-509.

11. Singh JA, Furst DE, Bharat A, Curtis JR, Kavanaugh AF, Kremer JM, et al. 2012 update of the 2008 American College of Rheumatology recommendations for the use of disease-modifying antirheumatic drugs and biologic agents in the treatment of rheumatoid arthritis. Arthritis Care Res (Hoboken). 2012;64:625-39.

12. Canadian Institute for Health Information $(\mathrm{CIHI})$. Wait times for priority procedures in Canada, 2014. Ottawa, ON, Canada: CIHI; 2014. https:// secure.cihi.ca/free_products/2014_WaitTimesAiB_EN.pdf. Accessed 5 Nov 2015

13. Wait Time Alliance (WTA). Time to close the gap: report card on wait times in Canada. Ottawa, ON, Canada: WTA; 2014. http://www.waittimealliance.ca/ wp-content/uploads/2014/06/FINAL-EN-WTA-Report-Card.pdf. Accessed 5 Nov 2015
14. Widdifield J, Paterson JM, Bernatsky S, Tu K, Thorne JC, Ahluwalia V, et al. The rising burden of rheumatoid arthritis surpasses rheumatology supply in Ontario. Can J Public Health. 2013;104:e450-5.

15. Badley EM, Canizares M, Gunz AC, Davis AM. Visits to rheumatologists for arthritis: the role of access to primary care physicians, geographic availability of rheumatologists, and socioeconomic status. Arthritis Care Res (Hoboken). 2015;67:230-9.

16. Kur J, Koehler B. Rheumatologist demographics in British Columbia: a looming crisis. B C Med J. 2011;53:128-31.

17. Badley EM, Canizares M, Mahomed N, Veinot P, Davis AM. Provision of orthopaedic workforce and implications for access to orthopaedic services in Ontario. J Bone Joint Surg Am. 2011;93:863-70.

18. Fyie K, Frank C, Noseworthy T, Christiansen T, Marshall DA. Evaluating the primary-to-specialist referral system for elective hip and knee arthroplasty. J Eval Clin Pract. 2014;20:66-73.

19. Hazlewood G, Lupton T, Martin L, Barr S. The impact of a centralized referral system in rheumatology. J Rheumatol. 2010;37:1288-9. doi:10.3899/jrheum.100360

20. Novak K, Veldhuyzen Van Zanten S, Pendharkar SR. Improving access in gastroenterology: the single point of entry model for referrals. Can J Gastroenterol. 2013;27:633-5.

21. van den Heuvel B, Vair B, Porter G, Klassen D, Inglis K, Bonjer HJ. Patient compliance with a group model of care: the hernia clinic. Can J Surg. 2012;55:259-63.

22. Damani Z, Conner-Spady B, Noseworthy TW. Value and acceptability of singleentry models in health care [poster P4-39]. Presented at the 35th Annual Meeting of the Society for Medical Decision Making. Bench, Bedside and Beyond: Medical Decision Making and Public Policy, Baltimore, MD, USA.

23. Health Quality Council of Alberta (HQCA). The Alberta Quality Matrix for Health. Calgary, AB, Canada: HQCA; 2005. https://d10k7k7mywg42z. cloudfront.net/assets/53288634f002ff214000014b/HQCA_Quality_Matrix_ 061713.pdf. Accessed 5 Nov 2015

24. Whittemore R, Knafl K. The integrative review: updated methodology. J Adv Nurs. 2005;52:546-53

25. Beyea S, Nicoll LH. Writing an integrative review. AORN J. 1998;67:877-80.

26. Barber C, Marshall D, Mosher D, Akhavan P, Tucker $L$ et al. Development of System-Level Performance Measures for Evaluation of Models of Care for Inflammatory Arthritis in Canada. J Rheumatol (In Press).

27. Frank C, Marshall D, Faris P, Smith C, Alberta Bone and Joint Health Institute. Essay for the CIHR/CMAJ award: improving access to hip and knee replacement and its quality by adopting a new model of care in Alberta. CMAJ. 2011;183:E347-50

28. Gooch K, Marshall DA, Faris PD, Khong H, Wasylak T, Pearce T, et al. Comparative effectiveness of alternative clinical pathways for primary hip and knee joint replacement patients: a pragmatic randomized, controlled trial. Osteoarthritis Cartilage. 2012;20:1086-94.

29. Gooch KL, Smith D, Wasylak T, Faris PD, Marshall DA, Khong H, et al. The Alberta Hip and Knee Replacement Project: a model for health technology assessment based on comparative effectiveness of clinical pathways. Int J Technol Assess Health Care. 2009;25:113-23.

30. Strömbeck B, Petersson IF, Vliet Vlieland TPM; EUMUSC.net WP6 group. Health care quality indicators on the management of rheumatoid arthritis and osteoarthritis: a literature review. Rheumatology (Oxford). 2013;52:382-90.

31. Fitch K, Bernstein SJ, Aguilar MD, Burnand B, LaCalle JR, Lázaro $P$, et al. The RAND/UCLA appropriateness method user's manual. Santa Monica, CA RAND Corporation; 2001. https://www.rand.org/content/dam/rand/pubs/ monograph_reports/2011/MR1269.pdf. Accessed 5 Nov 2015.

32. Dalal S, Khodyakov D, Srinivasan R, Straus S, Adams J. ExpertLens: a system for eliciting opinions from a large pool of non-collocated experts with diverse knowledge. Technol Forecast Soc Change. 2011;78:1426-44.

33. Khodyakov D, Hempel S, Rubenstein L, Shekelle P, Foy R, Salem-Schatz S, et al. Conducting online expert panels: a feasibility and experimental replicability study. BMC Med Res Methodol. 2011;11:174.

34. Basger BJ, Chen TF, Moles RJ. Validation of prescribing appropriateness criteria for older Australians using the RAND/UCLA appropriateness method. BMJ Open. 2012;2:e001431.

35. De Coster C, McMillan S, Brant R, McGurran J, Noseworthy T, Primary Care Panel of the Western Canada Waiting List Project. The Western Canada Waiting List Project: development of a priority referral score for hip and knee arthroplasty. J Eval Clin Pract. 2007;13:192-7.

36. Ackerman IN, Dieppe PA, March LM, Roos EM, Nilsdotter AK, Brown GC, et al. Variation in age and physical status prior to total knee and hip 
replacement surgery: a comparison of centers in Australia and Europe. Arthritis Rheum. 2009:61:166-73.

37. Finckh A, Liang MH, van Herckenrode CM, de Pablo P. Long-term impact of early treatment on radiographic progression in rheumatoid arthritis: a meta-analysis. Arthritis Rheum. 2006;55:864-72.

38. Yank G. Quality improvement in health care organizations: a general systems perspective. Behav Sci. 1995;40:85-103.

39. Marshall D, Christiansen T, Smith C, Howden JS, Werle J, Fyie K, et al. Voluntary versus involuntary waiting for joint replacements: new Alberta wait times rules for hip and knee arthroplasties, with provincial consensus. Healthc Q. 2012;15:37-42.

40. Rumble T, Kreder HJ. National Workforce \& Services Report. Westmount, QC, Canada: National Standards Committee, Canadian Orthopaedic Association; 2004. http://www.coa-aco.org/images/stories/news/NSC_Report_ 2004 final.pdf. Accessed 5 Nov 2015.

41. Natividad H. How has orthopaedics evolved? AAOS Now. 2011 Nov. http:// www.aaos.org/news/aaosnow/nov11/cover3.asp. Accessed 5 Nov 2015.

42. Canizares M, Badley E, Davis A, MacKay C, Mahomed N. Orthopaedic surgery in Ontario in the era of the Wait Time Strategy. Toronto: Arthritis Community Research \& Evaluation Unit, Toronto Western Research Institute; 2007. http://www.acreu.ca/pdf/pub5/07-02.pdf. Accessed 5 Nov 2015.

43. Noseworthy TW, MCGurran JJ, Hadorn DC, Steering Committee of the Western Canada Waiting List Project. Waiting for scheduled services in Canada: development of priority-setting scoring systems. J Eval Clin Pract. 2003;9:23-31.

44. Arnett G, Hadorn DC, Steering Committee of the Western Canada Waiting List Project. Developing priority criteria for hip and knee replacement: results from the Western Canada Waiting List Project. Can J Surg. 2003:46:290-6

45. Camacho FT, Feldman SR, Balkrishnan R, Kong MC, Anderson RT. Validation and reliability of 2 specialty care satisfaction scales. Am J Med Qual. 2009:24:12-8.

46. Clinical Indicators Team. NHS Outcomes Framework: 2014/15. Domain 4: ensuring that people have a positive experience of care. Wakefield, UK: NHS England; 2014. https://www.england.nhs.uk/resources-for-ccgs/out-frwrk/ dom-4/. Accessed 5 Nov 2015.

47. Deloitte \& Touche LLP and affiliated entities. Evaluation of central intake and assessment centres for hip and knee replacement. Ottawa, ON, Canada: Ministry of Health and Long-Term Care Ontario; 2011.

\section{Submit your next manuscript to BioMed Central and take full advantage of:}

- Convenient online submission

- Thorough peer review

- No space constraints or color figure charges

- Immediate publication on acceptance

- Inclusion in PubMed, CAS, Scopus and Google Scholar

- Research which is freely available for redistribution 